\title{
Development of a Constant Power AC/DC Converter for Point Heater Equipment
}

\author{
Min Il Hong, Chung Kwang Woo \\ Department of Railroad operation systems engineering, Korea National University of Transportation, Korea \\ \{mih9673\& ckw1201\}@ut.ac.kr
}

\begin{abstract}
Turnout equipment plays a vital role in the safe operation of railroad systems. It is of great importance in ensuring safety and punctuality, and in the smooth operation of point switching mechanisms. Failure of switching gear due to climatic conditions at their site of installation is a frequent occurrence, in particular, breakdown resulting from the effects of snow and ice or of piled-up snow. To prevent this happening, heating equipment can be installed to get rid of the ice and snow. Generally speaking, a point heater comprises a heating system, an electricity supply unit, and various kinds of sensor. However, overheating sometimes occurs owing to failures caused by inadequate sensor installation, resulting in the heater becoming unusable. Therefore, a converter is proposed to prevent this overheating by controlling the electricity supply to the heater while detecting the ambient temperature without the use of such sensors.
\end{abstract}

Index Terms - Pointer heater equipment, Constant power converter, AC/DC Converter

\section{Introduction}

Turnout equipment plays a vital role in the safe operation of railroad systems. Since such equipment is installed in the field, it is one of the facilities most affected by weather conditions. For this reason, we have safety features ranging from electrical to mechanical locking systems for the safe operation the track switching device. However, the line cannot be switched if it the lock fails to function well because of covering by heavy or frozen snow. Accordingly, various kinds of protective facility are employed in countries with developed railroads in order to prevent malfunction of the line switch due to climatic conditions. Among these is switch heating apparatus, but this has not been widely adopted up to now in Korea, where maintenance has generally been carried out manually. However, since the inauguration of high-speed rail on the Gyeongbu (Seoul-Busan) line, advanced railway technology has been imported and has begun to spread to other domestic lines.

Generally speaking, switch heater devices are designed to control the temperature by directly measuring the temperature of the heater. However, because they are attached directly to the rail, they are in a poor position to control the temperature by means of a temperature sensor, and in practice they are controlled manually. Controlling the temperature in this way, there is a concern that without the use of a sensor, burnout can occur due to overheating and that with reliance on manual control, the possibility of error is high.

Therefore, in this paper, we would like to propose an improved turnout heater temperature control method.

\section{Background}

A. Railway turnout switch heater system

When accumulated snow cover becomes heavy or freezes, movement of the switch may become impossible. This in turn may cause derailment or other failure. The function of point heater equipment is to prevent this problem by melting the ice and piled up snow.

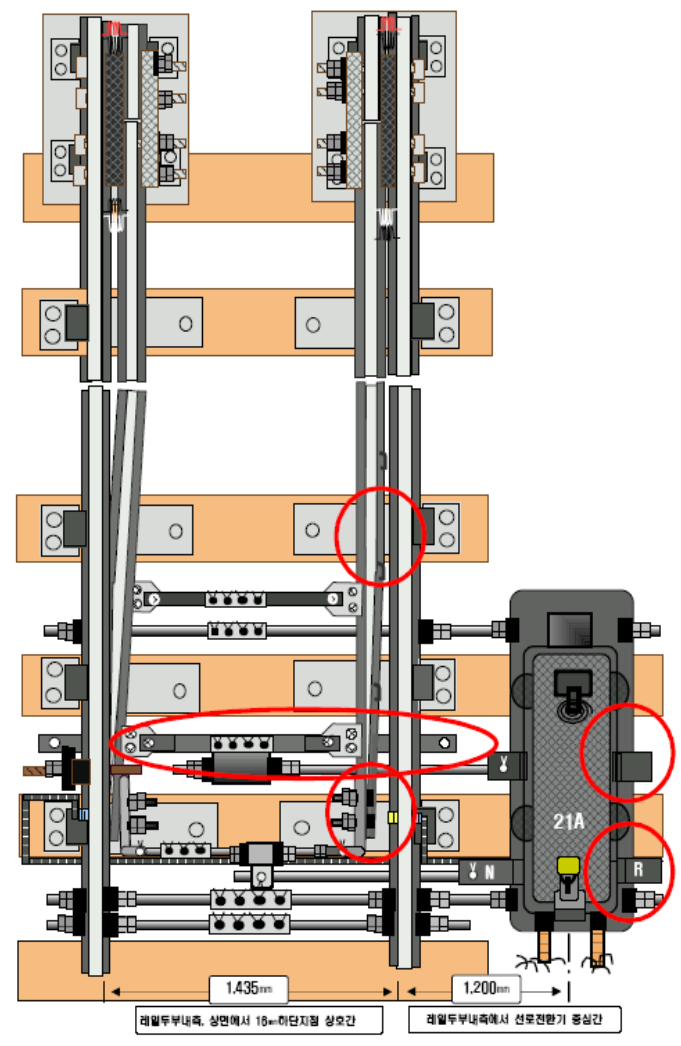

Fig. 1 Main locations of switch freezing

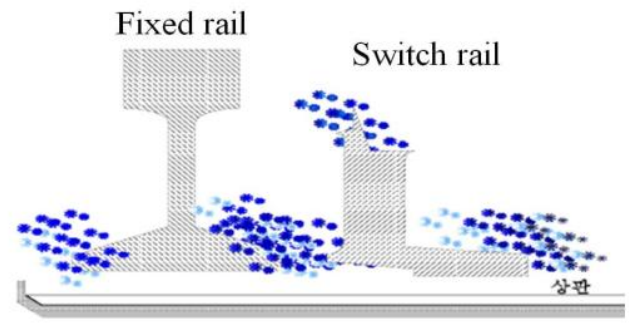

Fig. 2 Snow- covered 


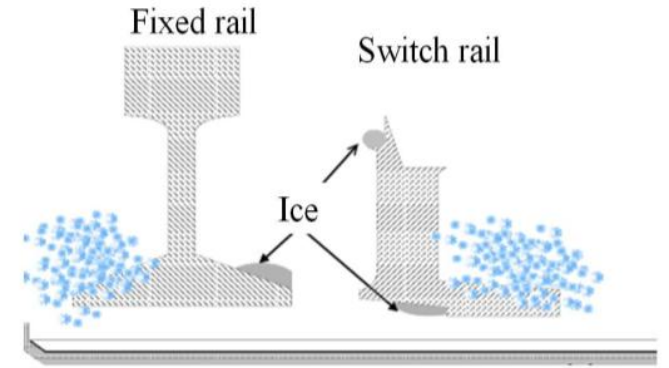

Fig. 3 Snow and ice- covered

Fig. 2 and Fig. 3 show how the process of freezing occurs between the switch rail and the fixed rail. If the snow piled up between the basic and the switch rail solidifies as a result of the pressure exerted by switching, then ice is formed, and the points cannot make close contact.

To prevent such failures, commonly used methods of melting the snow are watering, air heating, or electric heating. The electric point heater, the most convenient and the most widely used, has several advantages. It was installed a long time ago on the mountainous Taebaek line because of particularly heavy snow, but is nowadays also installed on points on the high-speed rail. According to the electricity business documentation of Korea Railroad Corporation (Korail), 1517 units of such snow melting devices are currently installed and used nationally both on high-speed and ordinary lines.

The power supply unit conveys electricity to the heater a constant voltage or constant current, which it receives from the panel of the machine control room. The temperature control prevents overheating of the heater by cutting off the power supply to the heating element when a certain temperature is exceeded.

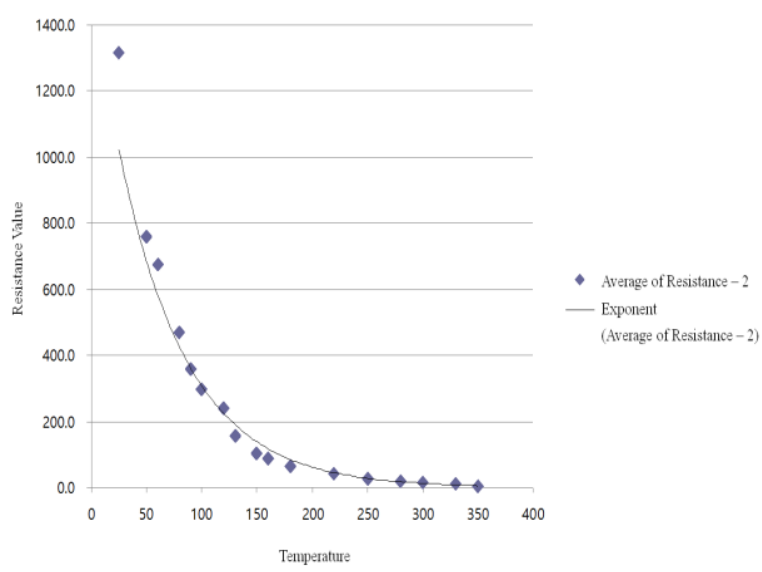

Fig. 4 Characteristic curve of negative resistance value

B. Resistance changes according to the temperature of the heating element

In general, the heating elements in common use are characterized by constant resistance: with increasing temperature, resistance value increases. However, the power of the heater must be controlled by frequent on/off switching in order to maintain a constant temperature based on the measured temperature of the heating element. Because of the constant level of resistance, there is less risk of overheating, while there is characteristically a decrease in caloric value when the heater reaches higher temperatures.

Another kind of element used in heaters has negative resistance characteristics. With this kind, resistance decreases as the temperature rises, and so a greater power supply is needed.

Fig. 4 shows the temperature-resistance curve of a heating element with negative resistance characteristics. The graph indicates a characteristic temperature of $350{ }^{\circ} \mathrm{C}$ when the resistance value is $4.8 \mathrm{ohm}$ and $25{ }^{\circ} \mathrm{C}$ when it is $1315 \mathrm{ohm}$. Because the load resistance decreases drastically as temperature increases, too high a load is placed on the power supply; heating becomes difficult at higher temperatures because of reduction of current. Therefore, it can be difficult to obtain optimal behavior of the heating device using a constant voltage or constant current supply.

If heating is to be smoothly achieved, a control method must be used that increases power supply to prevent overheating if the constant load resistance goes below a certain level. If we develop a power supply unit to use in a point heating device that will be able to maintain the temperature of the heater at a constant level without faults in ancillary equipment, it will be possible to control the rail system safely.

\section{The Present Experiment}

\section{A. The constant power control converter}

A turnout heating system must be designed so as to maintain a constant temperature and a constant supply of electricity. However, it has the characteristic that raising the temperature may increase or decrease the value of the resistance.

If we say the resistance is $R[\Omega]$ and the current flowing to the heater is $I[A]$ for $t[\mathrm{sec}]$, the calorific value of the heater may appear as:

$$
Q=0.24 I^{2} R t
$$

Also, when the load resistance of the heater is $\rho[\Omega]$, its cross-section $\left[\mathrm{m}^{2}\right]$, and its length is $1[\mathrm{~m}]$, the resistance and the current density in the heater $\delta\left[\mathrm{A} / \mathrm{m}^{2}\right]$ are:

$$
\begin{aligned}
& R=\rho \frac{l}{S}_{[\Omega]} \\
& \delta=\frac{I}{S}_{[\mathrm{A} / \mathrm{m} 2]}
\end{aligned}
$$

Using (2) and (3), (1) may be expressed as:

$$
Q=0.24 I^{2} R t=0.24(\delta S)^{2} \rho \frac{l}{S} t=0.24 \delta^{2} \rho S l t \text { [cal] }
$$


In the above formula, S x 1 indicates the volume V [m3] of the heater. Therefore the caloric value of the heater per unit volume may be expressed as:

$$
q=\frac{Q}{V}=0.24 \delta^{2} \rho t
$$

From (5), we can see that the caloric value per unit volume is proportional to the square of the load resistance and current density of the heating element. Furthermore the resistance of the heating unit changes according to the temperature. Therefore resistance changes in the heater bring about changes in current density, together with changes in the caloric value of the heater and in its temperature.

Normally, the power unit that supplies the heater uses a power rectifier controlling a constant voltage and current. If the resistance of the heater changes with temperature, the current density and wattage also change, which can lead to a sudden rise or drop in temperature. To maintain the heater at a constant temperature, it must use a power unit which can supply a constant current at changing resistance values. [1]

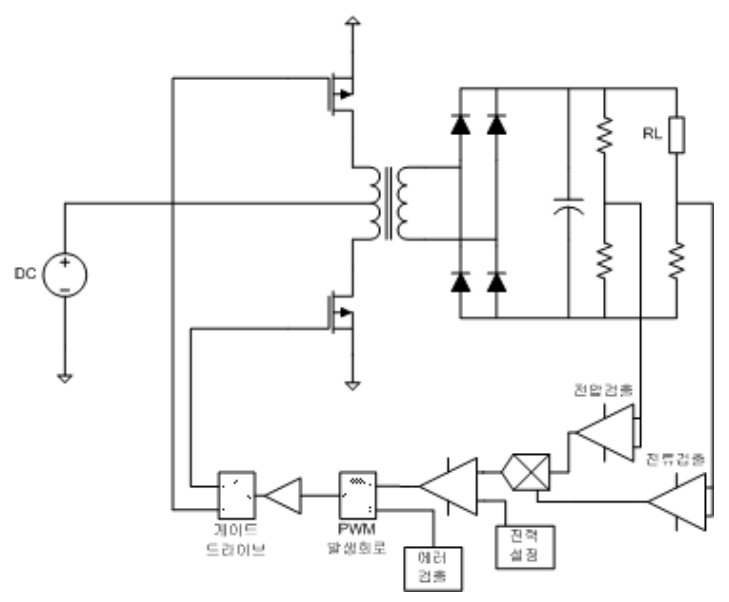

Fig. 5 Shows the structure of a constant power control converter for maintaining the heater system at a constant temperature

The converter is controlled by comparing the calculated voltage with a predetermined value. For this purpose we check the current and voltage of the converter output and through a multiplier, calculate the voltage value proportional to the power.

\section{Conduct of Experiment}

To realize the controlled constant power converter, a Push-Pull topology is used. [2] [3] The Push-Pull converter, compared with the widely-used $1 \mathrm{KW}$ medium power full bridge transformer, has a small number of switching elements. In addition, it has the advantage that the gate circuit can be produced simply and economically. [4]

TABLE I shows the specifications of the converter.
TABLE I Specification of Convert

\begin{tabular}{|c|c|}
\hline Input voltage & $12 \mathrm{~V}$ \\
\hline Output current & $600 \mathrm{~W}$ \\
\hline Switching frequency & $36 \mathrm{kHz}$ \\
\hline Switching element & IXGH24N60B \\
\hline Load resistance & $10[\Omega] \sim 20[\Omega]$ \\
\hline
\end{tabular}

Assuming a reduction in resistance from $20 \mathrm{ohm}$ to 10 ohm with increasing temperature of the switch heater element, the current output experiment is conducted with resistance decreasing from a starting level of $20 \mathrm{ohm}$ down to $10 \mathrm{ohm}$. Fig. 6 below shows the experimental set-up.

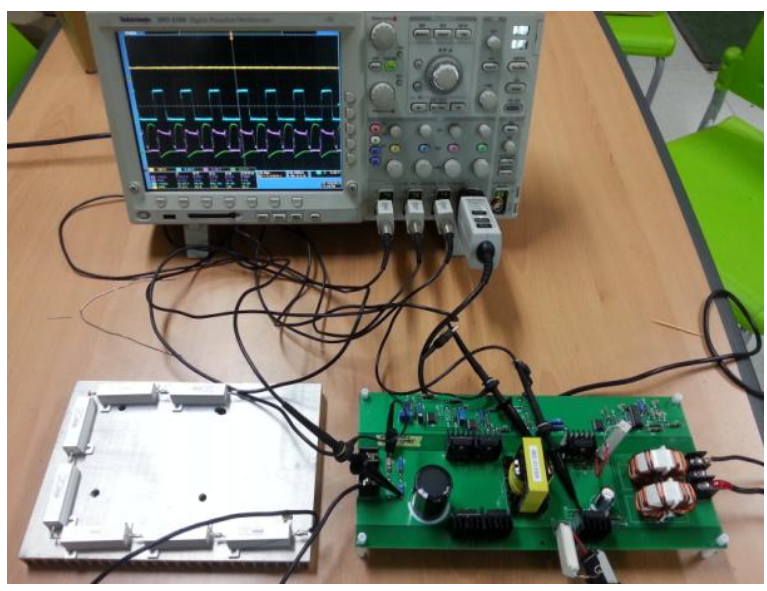

Fig . 6 The experimental set up

Since the heating element of the point heater has the characteristic that resistance changes with temperature, in order to control constant power, we must constantly maintain the multiple value of voltage and current at both ends of the element. We achieve control by detecting the voltage and current in the element by means of a comparator. In other words, the converter is designed to control the duty ratio.

In order to be able to put out the predetermined power with resistance value set at normal temperatures, even though the resistance in the heating system changes, we cannot put out more than the predetermined power.

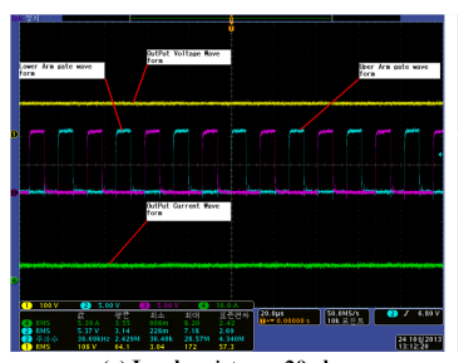

(a) Load resistance $20 \mathrm{ohm}$

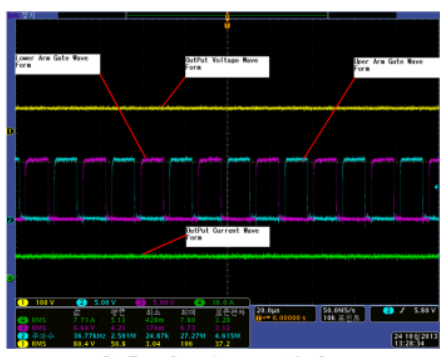

(b) Load resistance $10 \mathrm{ohm}$
Fig .7 Output voltage and corrent, Duty rate waveform

Fig.7 (a) shows duty ratio, output voltage and current when load resistance is at 20 ohms. 
When current is flowing at a load resistance of $20 \mathrm{ohms}$, output voltage is $108 \mathrm{~V}$, and output current is $108 \mathrm{~A}$. In this case, the duty ratio of one arm of the switch is $24 \%$.

Fig. 7 (b) shows output voltage and current, and duty ratio at a load resistance of $10 \mathrm{ohm}$. With resistance at $10 \mathrm{ohm}$, output voltage is $80 \mathrm{~V}$ and current is $7.7 \mathrm{~A}$. In this case, the duty ratio is $38 \%$.

Change in core resistance bring about change in feedback current. If resistance is increased, feedback current decreases, and if it is decreased, the current increases.

With load resistance at $20 \mathrm{ohm}$ and feedback voltage at $2.12 \mathrm{~V}$, duty ratio was adjusted to $24 \%$, but when load resistance was reduced to $10 \mathrm{ohm}$, feedback current increased to $2.98 \mathrm{~V}$ and output power was regularly adjusted by duty ratio being enhanced to $38 \%$.

Therefore, it is shown that if load resistance decreases, duty ratio is reduced, and if it increases, duty ratio is enhanced, and a constant output power level is possible.

Fig. 9 shows current and voltage at the switch. Switching this value was constantly maintained at $20 \mathrm{ohm}$. However, as duty ratio decreased, the RMS value at $10 \mathrm{ohm}$ was $14.2 \mathrm{~A}$, going down to $11.6 \mathrm{~A}$ at $20 \mathrm{ohm}$. Also, switching loss could be minimized with the switch voltage and current both at 0 when the on/off switch was operated,

The present experimental results showed that at $20 \mathrm{ohm}$, load resistance output power was measured at $583 \mathrm{~W}$, and at 10 ohm, it was $592 \mathrm{~W}$.

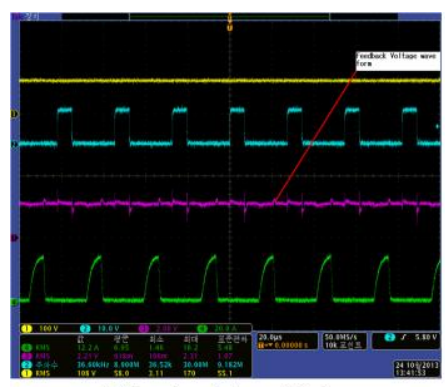

(a) Load resistance $20 \mathrm{ohm}$

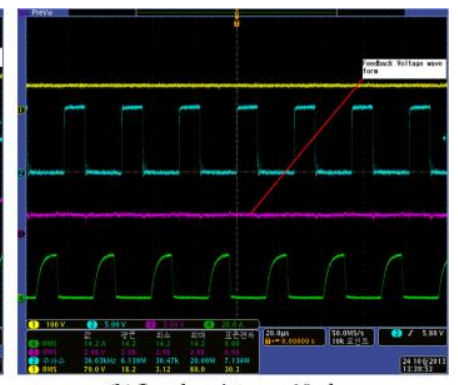

(b) Load resistance $10 \mathrm{ohm}$
Fig. 8 Feedback voltage change

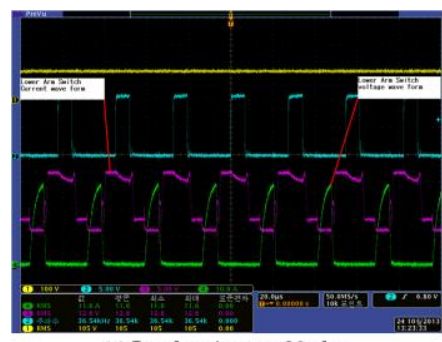

(a) Load resistance $20 \mathrm{ohm}$

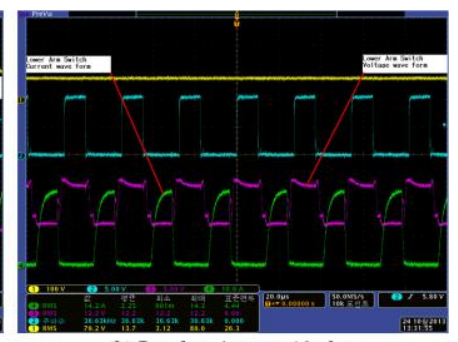

(b) Load resistance $10 \mathrm{ohm}$
Fig. 9 Switch current and voltage

\section{Conclusion}

Turnout equipment is among the most important devices demanded for safe operation and punctuality, and it is affected by a number of variables relating to temperature. The paper proposes a means of maintaining a constant temperature using a method of estimating caloric value comparative to power level without the use of a temperature sensor.

We designed a constant power supply unit which can output a constant level of heating of the turnout needed for snow-melting at changing levels of resistance, and tested its feasibility by a simulation.

The results of the simulation confirmed that the converter maintained a constant power output with resistance values changing from $100 \mathrm{ohms}$ to $200 \mathrm{ohm}$. The next step will be to manufacture a prototype to attempt to verify the ability of the device to achieve control of at real load resistances while maintaining a constant temperature.

The results confirmed that even if load resistance went down from $20 \mathrm{ohm}$ to $10 \mathrm{ohm}$, the converter still maintained a constant output power level.

\section{Acknowledgement}

The research was supported by a grant from the LINC (Leaders in INdustry-university Cooperation) Program of Korea National University of Transportation in 2013.

\section{References}

[1] Junming Tu, "Influence of mount structure on performance of ceramic Metal Halide Lamps", Industry Application, IEEE Transaction on Volume 44, Issue 6, Nov-Dec 2008, pp1987-1992.

[2] R.L. Steigerwald, "High Frequency Respondent Transistor DC-DC Converters", IEEE Trans. Ind. Electronics, Vol. IE-31, No.2, PP181, May, 1984.

[3] B. Swaminathan, V. Ramanarayanan, "A novel resonant transition PushPull DC-DC converter" 2004 Indian Institute of science, pp217 232.

[4] "SMPS Components and their effects on system design" Microchip Webseminars, 2006 